\title{
ATTENTION PROBLEMS IN PRIMARY SCHOOL CHILDREN, IN A RURAL SETTING, IN INDIA
}

Mubeen Taj M. D ${ }^{1}$, L. Agalya²

\section{HOW TO CITE THIS ARTICLE:}

Mubeen Taj M. D, L. Agalya. "Attention Problems in Primary School Children, in a Rural Setting, in India". Journal of Evolution of Medical and Dental Sciences 2014; Vol. 3, Issue 51, October 09; Page: 11954-11958,

DOI: $10.14260 /$ jemds/2014/3577

\begin{abstract}
Behavioral and emotional disorders include internalizing symptoms which affect the self and externalizing symptoms that impact others and the environment. Behavioral and emotional disorders occur frequently in the general population of children. It has been seen that female children had more of internalizing behavior problems whereas male children had more of externalizing symptoms. Psychiatric epidemiological studies from developed countries indicate that more than a quarter of children and adolescents meet lifetime criteria for a mental disorder. Among the behavioral disorders, the presence of attention problems is of importance as they have been shown to be associated with increasing academic difficulties. Among the various scales that have been used to study behavior problems, Achenbach Child Behavior Checklist has been the most widely used and has different versions for parents and teachers so that a complete assessment of a child's behavior can made with several inputs. This study aimed at assessing attention problems among primary school children, and to study the association between academic performance and attention problems using the Achenbach Child Behavior Checklist, using class teachers as raters, as interventions to reduce attention problems at an early stage may go a long way in improving the academic performance of the children. In this cross- sectional study, 198 children, 114 boys and 84 girls between 6 and 12 years of age, were rated on Achenbach Child Behavior Checklist (CBCL 6-18years) - Teacher Rating Form (TRF), revised 2001, by his/her class teacher. About 25 children had a score of more than $50 \%$ on the attention problems scale. No significant differences were found in the attention problem scores between boys and girls in the sample studied. There was no significant association between current academic performance as rated on the TRF and attention problem scores. School teachers, especially in the rural areas where resources are fewer, can prove to be valuable both for identifying behavior problems early and providing appropriate support to the child and his/her family as part of multidisciplinary mental health services providing team.
\end{abstract}

KEYWORDS: Attention problems, Achenbach Child Behavior Checklist, primary school children, teachers as raters.

INTRODUCTION: Behavioral and emotional disorders occur frequently in the general population of children. They include internalizing symptoms which affect the self and bring about subjective distress or psychological pain and externalizing symptoms that impact others and the environment due to acting out behavior. Internalizing symptoms include depression, anxiety, obsessive, compulsive, psychotic and schizoid symptoms while externalizing symptoms include hyperactive and impulsive behaviors, aggressive and violent behaviors, features of mania and hypomania, oppositional behaviors and substance abuse.

Community studies on emotional/behavioral disorders in children and adolescents conducted in India have yielded disparate point prevalence estimates (2.6\%-35.6\%).[1-3] 


\section{ORIGINAL ARTICLE}

The variation in the estimates may be due to differences in the diagnostic criteria, sampling methods, instruments and informants chosen across the studies.

Some of the factors that influence the psychosocial development of a child include genetic endowment, parents, siblings and extended family, ordinal position in the family, culture and environment, socioeconomic status, peers, and importantly, the school and the school environment. This involves looking at the school as a place where the child's values and behaviors are influenced through interactions with others.

Research has shown that not just in children diagnosed with ADHD, attention problems are associated with diminished academic success even in non-diagnosed children. Merrell and Tymms (2001) reported that teacher ratings of attention problems at the beginning of formal schooling predicted increasing academic difficulties over the next year.[5] Rabiner and Murray (2002) working with a sample of 620 first graders, reported that teacher-rated attention problems were the strongest predictor of low academic achievement and that students in the top 15\% for teacher ratings of DSMIV inattentive symptoms were four to seven times more likely to be rated below grade level in reading, math, and written language. ${ }^{[6]}$

This was true even after controlling for gender, ethnicity, school and a variety of other behavioral/emotional problems like hyperactivity, oppositional behavior and anxiety. Rabiner, Coie, and the Conduct Problems Prevention Research Group (CPPRG 2000), followed up 387 students from kinder garden through the end of fifth grade and found that attention problems during first grade predicted the development of reading difficulties that were evident 5 years later, even after controlling for IQ, other behavior problems, and prior reading achievement.

Although withdrawn, somatic complaints, delinquent behavior, and aggressive behavior syndromes exhibited significant zero order correlations with the academic achievement measures, each of these relationships was mediated by attention problems. Children under 16 years of age constitute over $40 \%$ of India's population and estimating the prevalence of psychiatric problems in children and adolescents and also identifying them early is of importance in planning and providing appropriate mental health services to this vulnerable population. ${ }^{[4]}$

\section{OBJECTIVES:}

1. To study attention problems among primary school children in a rural area.

2. To study the association between academic performance and attention problems.

METHODOLOGY: This cross-sectional study was conducted in three primary government schools located in a village in Dharmapuri district of the state of Tamilnadu. Children from these schools between 6 and 12 years of age, belonging to both the sexes were included as subjects. Known cases of moderate-severe mental retardation, head-injury or post encephalitic sequelae were excluded from the study.

Each subject was rated on Achenbach Child Behavior Checklist (CBCL 6-18years)-Teacher Rating Form (TRF), revised 2001.The CBCL was developed to cover a broad range of symptoms and several positive attributes related to academic and social competence. The checklist presents items related to mood, frustration tolerance, hyperactivity, oppositional behavior and others. The teacher version has 113 items to be rated 0 (not true), 1 (sometimes true) or 2 (very true). 


\section{ORIGINAL ARTICLE}

The CBCL-Teacher Rating Form was rated for every student included in the study by his/her class teacher. 26 items in the TRF pertain to attention problems and the scores can range from $0-52$. Informed consent was taken from the heads of the three primary schools involved in the study and the teachers and strict confidentiality was maintained. The data thus obtained was analyzed using relevant statistical methods.

RESULTS OF THE STUDY: 198 primary school children were included in the study. All the children came from families where the parents were working as agricultural labourers or in the construction industry as labourers. None of the children had any chronic illness or disability (either physical or mental). Out of the 198 children included in the study 114 were boys while 84 were girls (Table 1 ).

The mean age of the primary school children was 8.29 years (Table 2). 25 children (12.6\%) scored more than $50 \%$ (more than 26 ) on the attention problems scale and the mean scores were 14.39 (Table 3). Pearson's correlation was used to study the association between academic performance and attention problems. This study showed a no significant correlation between the two variables (Table 4). There was no significant difference in the attention problem scores between boys and girls in this sample (Table 5).

\begin{tabular}{|c|c|c|}
\hline Sample & Boys & Girls \\
\hline $\mathrm{N}=198$ & 114 & 84 \\
\hline
\end{tabular}

Table 1: GENDER

\begin{tabular}{|c|c|c|c|}
\hline Sample & Range & Mean & SD \\
\hline N=198 & 7-12 years & 8.29 & 1.137 \\
\hline \multicolumn{4}{|c}{ Table 2: AGE OF THE SUBJECTS } \\
\hline
\end{tabular}

\begin{tabular}{|c|c|c|}
\hline No. of Subjects Scoring $\mathbf{> 5 0} \%$ & Mean & SD \\
\hline 25 & 14.39 & 7.42 \\
\hline \hline
\end{tabular}

Table 3: MEAN ATTENTION PROBLEMS SCORE OF THE SUBJECTS

\begin{tabular}{|c|c|c|c|}
\hline \multicolumn{4}{|c|}{ Correlations } \\
\hline & & $\begin{array}{c}\text { Academic } \\
\text { performance }\end{array}$ & $\begin{array}{c}\text { Attention } \\
\text { Problems }\end{array}$ \\
\hline $\begin{array}{c}\text { Academic } \\
\text { performance }\end{array}$ & Pearson Correlation & 1 & .005 \\
\hline & Sig. (2-tailed) & & .943 \\
\hline & $\mathrm{N}$ & 198 & 198 \\
\hline Attention Problems & Pearson Correlation & .005 & 1 \\
\hline & Sig. (2-tailed) & .943 & \\
\hline & N & 198 & 198 \\
\hline \multicolumn{4}{|c|}{ No significant correlation between the two variables } \\
\hline \multicolumn{2}{|c|}{ Table 4: ASSOCIATION BETWEEN ACADEMIC } \\
PERFORMANCE AND ATTENTION PROBLEMS \\
\hline
\end{tabular}




\section{ORIGINAL ARTICLE}

\begin{tabular}{|c|c|c|c|c|c|c|}
\hline \multirow{5}{*}{$\begin{array}{l}\text { Boys } \\
\text { Girls }\end{array}$} & \multicolumn{6}{|c|}{ Test value $=0$} \\
\hline & \multirow{2}{*}{$\mathbf{t}$} & \multirow{2}{*}{ df } & \multirow{2}{*}{ Sig(2-tailed) } & \multirow{2}{*}{ Mean diff } & \multicolumn{2}{|c|}{$95 \%$ confidence interval of the diff } \\
\hline & & & & & Lower & Upper \\
\hline & 20.848 & 113 & .000 & 14.84211 & 13.4316 & 16.2526 \\
\hline & 17.603 & 83 & .000 & 13.77381 & 12.2175 & 15.3301 \\
\hline
\end{tabular}

DISCUSSION: In this study about $12.6 \%$ of the children scored more than $50 \%$ on the attention problem scale of the CBCL-TRF. Attention problems predict reduced first grade reading achievement even after controlling for IQ and earlier reading ability in the above mentioned studies. Intervention was associated with modest reading achievement benefits for inattentive children without early reading difficulties and substantial benefits for children with early learning difficulties who were not inattentive, in the previous studies.

Results underscore the need to develop effective academic interventions for inattentive children, particularly those with co-occurring reading difficulties. But in this study there was no significant association between scholastic performance and attention problem scores. Usage of specific tests for reading and written language may need to be used to study the association with attention problem scores as used in the above mentioned studies.

Extra instruction in these skills, particularly in a one- on- one context where children with attention problems are typically able to focus more consistently, would thus presumably be effective in preventing these children from falling significantly behind their peers in the acquisition of early reading skills.

CONCLUSION: Regarding management in child psychiatry, emphasis is on changing the attitudes of parents, reassuring and retraining children, working with the family and coordinating the efforts of others who can help these children especially at school. In this study the class teachers were the informants and CBCL-TRFs were the instruments used.

About $12.6 \%$ of the children scored more than $50 \%$ on the attention problem scale of the TRF. There was no difference between boys and girls with regard to attention problem scores on the CBCL. There was no significant association between academic performance as measured by the CBCL and attention problems score which may underline the need for more specific tests to assess academic performance.

RECOMMENDATIONS: A child generally spends around 6-7hrs of his/her waking time in school and hence class teachers would be able to provide more inputs regarding a child's behavior, his/her strengths and weaknesses. This will be of more significance especially in the rural areas where resources may not be as plentiful as in urban areas.

The student-teacher ratio may be kept at the minimum possible, in schools, so that the teacher would be able to give more of his/her time to each child under her tutelage. Mental health professionals may be made part of the school team so that the behavior problems that have been identified by the parents/teachers can be dealt with appropriately. 


\section{ORIGINAL ARTICLE}

\section{REFERENCES:}

1. Nandi DN, Banerjee G, Mukherjee SP, Ghosh A, Nandi PS, Nandi S. Psychiatric morbidity of a rural Indian community. Changes over a 20-year interval. Br J Psychiatry 2000; 176: 351-356.

2. Rahi M, Kuncavat AP, Garg S, Singh MM. Socio demographic co-relates of psychiatric disorders. Indian J Pediatr 2005; 72: 395-398.

3. Muzammil K, Kishore S, Semmal J. Prevalence of psychosocial problems among adolescents in distinct Dehradun, Uttarakhand. Indian J Public Health 2009; 53: 18-21.

4. Pratap S, Rajesh S. The need for national data on epidemiology of child and adolescent mental disorders. J Indian Association Child Adolesc Mental Health 2008; 4 [2]: 22-27.

5. Merrell C., \& Tymms, P.B. Inattention, hyperactivity and impulsiveness: Their impact on academic achievement and progress. British Journal of Educational Psychology 2001; 71: 43-56.

6. Rabiner D.L., Coie J.D., \& Conduct Problems Prevention Research Group. Early attention problems and children's reading achievement: A longitudinal investigation. Journal of the American Academy of Child and Adolescent Psychiatry. 2000; 39: 859-867.

\section{AUTHORS:}

1. Mubeen Taj M. D.

2. L. Agalya

\section{PARTICULARS OF CONTRIBUTORS:}

1. Assistant Professor, Department of Psychiatry, A.C.S. Medical College, Chennai.

2. Final Year M.B. B. S. Student, A.C.S. Medical College, Chennai.

\section{NAME ADDRESS EMAIL ID OF THE} CORRESPONDING AUTHOR:

Dr. Mubeen Taj M. D,

Assistant Professor,

Department of Psychiatry,

A.C.S. Medical College,

Poonamalle High Road,

Vellappanchavadi, Chennai-600077.

Email: mubeen_taj05@hotmail.com

Date of Submission: 22/09/2014.

Date of Peer Review: 23/09/2014.

Date of Acceptance: 01/10/2014.

Date of Publishing: 08/10/2014. 